\title{
Revista Interdisciplinar em \\ Estudos de Linguagem
}

DOI https://doi.org/10.29327/2.1373.2.2-15

ÁFRICA E BRASIL:

SABERES DOS POVOS EM PROL DO LETRAMENTO RACIAL CRÍTICO

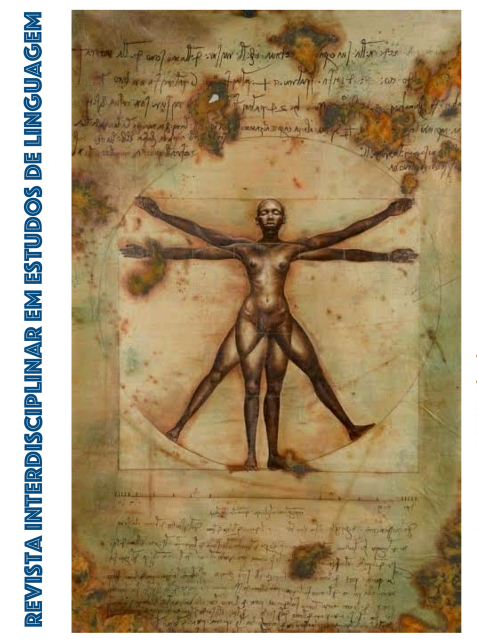

Este trabalho traz algumas reflexões acerca de um projeto realizado em uma escola municipal das séries iniciais do ensino fundamental, que debateu identidades de raça. Partiu da experiência com crianças negras refletindo sobre suas identidades de raça. $O$ objetivo era entender quais impactos ocorreriam na comunidade com as práticas adotadas de fortalecimento das identidades raciais negras. Para esta discussão utilizamos como arcabouço teórico Cavalleiro (1998); Ferreira (2015a, 2015b); Gomes (2002); Silva (2000); Oliveira e Moura (2005). Do ponto de vista metodológico, trata-se da metodologia de projetos, amparada pelo Letramento Racial Crítico (FERREIRA, 2015b). Como resultado enfatizamos o desenvolvimento da criticidade das crianças, o envolvimento de todas (os) os (as) funcionárias (os) da escola e a transposição do debate além dos muros da escola. Assim, foi possível trazer novos olhares ao tema identidades de raça na escola e a promoção do letramento racial crítico.

Palavras-chave

Racismo; Infância; Escola; Letramento Racial Crítico

Samantha Schäfer

samanthaschafer@hotmail.com • https://orcid.org/0000-0002-9977-8087

Aparecida de Jesus Ferreira

aparecidadejesusferreira@gmail.com•https://orcid.org/0000-0002-3728-0793 


\section{INTRODUÇÃO}

Os séculos de escravização e políticas coloniais desenvolveram práticas de exclusão que estão arraigadas na sociedade brasileira. Ainda no século XXI, há práticas racistas a serem rompidas e que foram estabelecidas lá no período colonial. Todos os dias a mídia noticia novos episódios de racismo, preconceito e discriminação racial. Todos nós, de uma forma ou de outra, já presenciamos ou nos foi contado algo nesse sentido. O racismo estrutural faz parte da sociedade em que vivemos e, infelizmente, vemos em grande escala se perpetuar também no ambiente escolar.

Apesar de sermos, incontestavelmente, uma nação multirracial e pluriétnica, de grande diversidade cultural, a escola brasileira parece não ter abarcado toda essa realidade, oferecendo prejuízo na aprendizagem das crianças e jovens dos estratos sociais mais pobres, constituídos, na sua grande maioria de negras (os). Por acreditarmos que uma mudança de paradigma dentro das escolas pode contribuir na adoção de posturas políticas contra o racismo, preconceito e discriminação racial, é que esta experiência busca uma educação de qualidade para todos com equidade. $O$ objetivo do projeto responde a seguinte pergunta: Quais impactos ocorreram na comunidade com as práticas adotadas de fortalecimento das identidades raciais negras? Para essa discussão utilizamos como arcabouço teórico Cavalleiro (1998); Ferreira (2015a, 2015b); Gomes (2002); Silva (2000); Oliveira e Moura (2005). Do ponto de vista metodológico, trata-se da Metodologia de Projetos, amparada pelo Letramento Racial Crítico (FERREIRA, 2015a).

Desta forma, este relato de experiência está estruturado da seguinte forma: em primeiro lugar trazemos as reflexões teóricas, em segundo lugar descrevemos as metodologias adotadas, em que estão presentes os objetivos e a descrição do contexto. Em terceiro lugar, trazemos os procedimentos adotados, o relato da experiência e finalmente os resultados e considerações. 


\title{
1. REFLEXÕES TEÓRICAS
}

Tivemos como motivação a experiência com alunas (os) de seis anos, negros e negras, que ao ingressarem na escola já apresentam uma autoestima baixa com relação à identidade racial à qual pertencem. Em contrapartida, as crianças brancas, em muitas situações, assumiam atitudes preconceituosas, racistas e discriminatórias atribuindo caráter pejorativo à cor da pele negra. Infelizmente, há um grande número de profissionais da educação que não acreditam que as crianças possam reproduzir o racismo. Gomes (2002) nos esclarece:

\begin{abstract}
Quando participamos de eventos, seminários e discussões educacionais do campo da Educação Infantil é perceptível a resistência de algumas pesquisadoras em aceitar a raça como uma importante categoria de análise. Há relutância na compreensão de que as crianças pequenas entre si, na relação com os adultos e o mundo que as cerca, já nutrem interpretações e realizam ações pautadas na diferença racial. E, mais, esses comportamentos apresentam estereótipos raciais negativos em relação aos negros (GOMES, 2002, p. 1017).
\end{abstract}

Para tanto, decidimos desenvolver um projeto que vai ao encontro da Lei Federal $n^{\circ}$ 10.639/03, que alterou a Lei $n^{\circ}$ 9.394/96 (Lei de Diretrizes e Bases da Educação Nacional), incluindo "no currículo oficial da Rede de Ensino a obrigatoriedade da temática História e Cultura Afro-Brasileira" (BRASIL, 2003). Entre as alterações constantes na nova Lei, foi acrescentado o Art. 26A, onde se lê que "Nos estabelecimentos de ensino fundamental e médio, oficiais e particulares, torna-se obrigatório o ensino sobre História e Cultura Afro-Brasileira" (BRASIL, 2003). No entanto, para implementar o ensino de História e Cultura Afro-Brasileira é importante ler o Parecer das Diretrizes Curriculares Nacionais para educação das relações étnico-raciais e para o ensino de História e Cultura Afro-Brasileira e Africana, que traz sugestões de implementação (BRASIL, 2005).

Assim, como a lei sugere, o projeto trouxe as pessoas negras como sujeitos históricos, valorizando-os, trazendo ao conhecimento das (os) alunas (os) as ideias de importantes intelectuais brasileiros, negros e negras para que conheçam, compreendam e valorizem a História da Cultura Afro-Brasileira e dessa forma tenham condições de desconstruir as ideias que levam ao racismo. 
Promover a valorização e o reconhecimento da diversidade étnico racial na educação brasileira a partir do enfrentamento estratégico de culturas e práticas discriminatórias e racistas institucionalizadas presentes no cotidiano das escolas e nos sistemas de ensino que excluem e penalizam crianças, jovens e adultos negros e comprometem a garantia do direito à educação de qualidade de todos e todas (BRASIL, 2003, p. 11).

O intuito deste projeto seria colaborar no rompimento de uma educação eurocêntrica. Dessa forma, trabalhamos a valorização da Cultura Africana e AfroBrasileira em uma escola municipal na região de Ponta Grossa- PR, a fim de contribuir para a mudança desse quadro já mencionado anteriormente, de prejuízo, principalmente às crianças negras. Utilizamos, como base neste projeto, o Letramento Racial Crítico, por se dedicar aos estudos sobre questões raciais e suas influências. Ao optar por esta análise, a partir Letramento Racial Crítico, não nos referimos apenas à identidade negra, mas também à identidade branca, conforme afirma Ferreira (2015a, p. 36):

[...] para termos uma sociedade mais justa e igualitária, temos que mobilizar todas as identidades, ou seja, a identidade racial branca e a identidade racial negra para refletir sobre raça, racismo e possíveis formas de letramento racial crítico no contexto escolar em todas as disciplinas do currículo escolar.

Dessa forma, insistimos na importância do Letramento Racial Crítico pela forma complexa com que trata a raça, como influenciadora das diversas experiências dos indivíduos de uma sociedade. Assim sendo, exige que olhemos mais adiante, de forma crítica, num horizonte onde raça funciona como um instrumento de controle social, em que brancos não se racializam por serem considerados a norma, o padrão universal.

Normalizar significa eleger - arbitrariamente - uma identidade específica como parâmetros, em relação a qual, outras identidades são avaliadas e hierarquizadas. Normalizar significa atribuir a essa identidade todas as características positivas possíveis, em relação às quais todas as outras identidades só podem ser avaliadas de forma negativa à identidade normal e "natural", desejável e única (SILVA, 2000, p. 83).

Portanto, uma criança negra que vivencia situação de racismo, preconceito e discriminação com relação ao seu corpo, a partir de estereótipos que desprivilegiam a sua identidade racial negra, e são reforçados no ambiente escolar pode não construir uma imagem positiva de si mesmo. As crianças que lidam com situação de não identificação de sua identidade poderão passar por inúmeros conflitos desencadeando comprometimento na sua socialização e aprendizagem. 
A dor de ser negro e discriminado é algo que se carrega por toda a vida e as crianças negras precisam enfrentar essa situação diariamente. A sub-representação entre as personagens negras foi apontada no trabalho de Cavalleiro (1998), a qual reiterava a tese da hierarquização da categoria branca como padrão de humanidade como segue abaixo:

[...] a disparidade nas representações de personagens negras e brancas pode ser fonte de rebaixamento de autoestima e um facilitador para a construção de autoconceito negativo por parte de crianças negras. E, diametralmente, que pode ser fonte de construção de um sentimento de superioridade por parte das crianças brancas, pelo fato de terem pele branca e fazerem parte, portanto, do grupo que constitui maioria em ilustrações e referências culturais e histórias nesse tipo de material [...] (CAVALLEIRO, 1998, p. 83).

Dessa forma, a escola é o ambiente propício ao debate sobre o respeito das identidades sociais de raça, e o valor da diversidade. A escola que deseja se constituir democrática deve respeitar todos os segmentos da sociedade, privilegiar a inclusão, reconhecer e combater as relações discriminadoras, desconstruir as hierarquias entre as culturas. É o que buscamos com a realização deste trabalho.

\section{METODOLOGIA: OBJETIVOS E CONTEXTO}

O trabalho realizado foi ancorado na metodologia com projetos, pois, segundo Oliveira e Moura (2005), ao abordar esse instrumento na construção do conhecimento escolar, valoriza-se uma prática pedagógica que estimula a iniciativa dos alunos através da pesquisa, desenvolve o respeito às diversidades pela necessidade do trabalho em equipe, incentiva o saber ouvir e expressar-se, o falar em público e o pensamento crítico autônomo. Esta autonomia, que vai sendo conquistada através da pesquisa, com toda a diversidade de caminhos percorridos e as competências que as (os) alunas (os) vão desenvolvendo através dessa prática, visa a promover sua autonomia intelectual (OLIVEIRA e MOURA 2005).

O trabalho com projetos quer mais do que romper com as velhas aulas expositivas, lineares, em que as (os) alunas (os) pouco interagem com as (os) colegas e com a (o) própria (o) professora (or). O que se propõe é novas formas de ensinar e aprender levando em conta o envolvimento de alunas (os) e professoras (es) com o 
conhecimento. Nessa perspectiva, rompe-se com a concepção tão difundida, que atribui ao desenvolvimento do intelecto, dos aspectos cognitivos e racionais, um lugar de destaque na educação, relegando ao segundo plano os aspectos emocionais e afetivos de nossa vida. Assim é que a educação tradicional e os currículos escolares, ao trabalharem de maneira puramente cognitiva a matemática, a língua, as ciências, a história, etc., acabam por priorizar apenas um desses aspectos constituintes do psiquismo humano, em detrimento do outro, ou dos outros (ARANTES, 2003).

O trabalho educativo na Metodologia de Projeto favorece a autonomia do aluno, no sentido de estimulá-lo a realizar aprendizagem tanto no aspecto individual como no coletivo. Sendo assim, há várias características que envolvem essa Metodologia de Projetos segundo Mercado (1999, p.81). São elas:

Estabelecer relações entre os vários aspectos que estão envolvidos no tema, o assunto que está sendo discutido; realizar relações com outros assuntos já vistos; desenvolver a capacidade de se colocar questões e de ressignificar as informações que já havia construído em função dos novos fatos e conhecimentos apresentados e discutidos pelo professor ou pelo grupo; reconhecer contradições e construir argumentações consistentes em favor de seu ponto de vista ou visão sobre o tema em questão ( MERCADO, 1999, p. 81).

Portanto, a teoria de Mercado (1999) se coaduna com o que diz Ferreira (2015b) em suas reflexões sobre raça e racismo quando fala em Letramento Racial Crítico:

Letramento Racial Crítico é refletir sobre raça e racismo. Possibilita-nos ver o nosso próprio entendimento de como raça e racismo são tratados no nosso dia a dia, e o quanto raça e racismo têm impacto em nossas identidades sociais e em nossas vidas, seja no trabalho, seja no ambiente escolar, universitário, seja em nossas famílias, seja nas nossas relações sociais (FERREIRA, 2015b, p. 138).

Entender que raça e racismo permeiam a nossa sociedade e tratar sobre identidade racial negra no contexto escolar é de extrema relevância. É importante, neste momento, retomar que o projeto tem como objetivo entender: Quais impactos ocorreram na comunidade com as práticas adotadas de fortalecimento das identidades raciais negras? No relato que segue, ficam evidentes quais foram os resultados e como 0 Letramento Racial Crítico colaborou para esses resultados. 


\section{RELATO DE EXPERIÊNCIA DE UM PROJETO REALIZADO EM UMA ESCOLA MUNICIPAL DAS SÉRIES INICIAIS DO ENSINO FUNDAMENTAL, ABORDANDO IDENTIDADES DE RAÇA}

Acreditamos que as (os) alunas (os) são seres complexos e que necessitam desenvolver-se em todas as suas potencialidades. Morin (2000, p. 32) afirma "trazemos, dentro de nós, o mundo físico, o mundo químico, o mundo vivo, e, ao mesmo tempo, deles estamos separados por nosso pensamento, nossa consciência, nossa cultura". Sendo assim, cabe às (aos) docentes refletir sobre essa separação das disciplinas, que pode deixá-las mais distantes e enfadonhas e consequentemente sem sentido para as (os) alunas (os). Concordamos com Morin (2000, p. 32) quando diz que "Conhecer o humano não é separá-lo do Universo, mas situá-lo nele." Dessa forma, utilizamos a Metodologia de Projetos, que vai muito além do saber, pois se relaciona às possibilidades de viver no mundo atual e não ficar à margem dele e ser, ainda, capaz de enfrentar uma sociedade que se renova constantemente.

Nesta perspectiva, as crianças realizaram as atividades do projeto como protagonistas do seu próprio conhecimento.Utilizamos um problema que demandava soluções urgentes dentro da escola, que era a discriminação racial que acontecia regularmente. A questão étnico-racial foi trabalhada, em uma escola do ensino fundamental inicial, de maneira dinâmica e interdisciplinar a partir de livros com personagens negras (os) protagonistas, escolhidos de acordo com a idade das crianças que variam de 5 a 10 anos. O Projeto iniciou em Fevereiro de 2017, início do ano escolar, e se estendeu até o mês de novembro. Apesar da variedade de atividades envolvidas, foram selecionadas algumas, que seguem descritas:

1) Para iniciar os trabalhos foi feita a contação da história do livro: "Cada um com seu jeito, cada jeito é de um!" de Lucimar Rosa Dias. Após sua interpretação e compreensão, foi propiciado o empréstimo do livro às (aos) alunas (os) para que realizassem a leitura individual da obra. Neste contexto, pôde ser debatido sobre a identidade, ao trabalhar com essa personagem negra que canta, joga bola, monta quebra cabeça, que é apresentada sem estereótipos e de forma positivada. Após o entendimento do conteúdo do livro, foi realizada uma roda de conversa sobre o que é beleza. A cada dia uma (um) 
aluna (o) teve a oportunidade de levar a sacola com o livro trabalhado para ler em companhia dos familiares.

2) A mascote da turma: a chegada de uma boneca negra à sala de aula, como representação de uma menina africana (mascote), e que participou durante o ano todo da rotina escolar. Após pesquisar sobre os nomes africanos, foi escolhido um nome para a menina, Leiza. A turma justificou a escolha do nome pelo seu significado "consagrado a Deus".

3) Variedade textual: CONTO: Foi instituída a semana do conto africano: um conto africano novo foi contado a cada dia durante duas semanas e assim puderam conhecer traços da cultura africana. POESIAS: variadas que falam da diferença, em seguida um debate sobre ser diferente, sobre o respeito a todos. TEXTO NÃO VERBAL E DE PESQUISA: localização do continente africano no mapa, no globo e em pesquisas na internet. As (os) alunas (os) puderam procurar curiosidades sobre esse continente e vislumbrar sua beleza e grandiosidade, além de conhecer um pouco mais dessa cultura. Através do painel confeccionado pela turma puderam compartilhar o trabalho com as outras turmas. BIOGRAFIA: Zumbi dos Palmares e Dandara.

4) Interdisciplinaridade: PROFESSORA DE EDUCAÇÃO FÍSICA: trabalhou a luta de origem africana Maculelê e diversas brincadeiras brasileiras como: escravos de Jó, que foi explicado e trabalhado de forma crítica, barra manteiga, e brincadeiras africanas como: bambolê e pega o bastão (Egito), mamba (África do Sul), saltando o feijão (Nigéria), terra mar (Moçambique), Tsoro Yematatu (Zimbábue), bole-bole (Gana), todas contextualizadas de acordo com a região de origem através de mapas e do globo. PROFESSORA DE EXPRESSÃO CORPORAL: trabalhou as danças típicas de várias regiões da África, como a dança de resistência negra, o Jongo. PROFESSORA DE ARTES: confeccionou máscaras, que tem grande importância na cultura africana, e ainda, a confecção do cabelo afro com lã (que foi sugestão das (dos) próprias (os) alunas (os)).

5) Campanha contra o racismo (3 de Julho- Dia Nacional de Combate à discriminação racial), nos pequenos gestos do dia a dia, dentro da escola, estendendo- se à 
comunidade, como no Posto de Saúde e no Centro de Educação Infantil (CMEI). Foi estimulada a desconstrução de expressões de cunho racista, "Gato preto não dá azar não!", "Meu cabelo afro é bom e ainda faço vários penteados!", entre outros.

6) Passeio: $O$ passeio à Colônia Sutil (comunidade quilombola) foi de extrema importância para que as (os) alunas (os) visualizassem como é a vida das (dos) descendentes de escravizadas (os), dentro de sua região dos Campos Gerais. Puderam entrar em contato com as (os) quilombolas, fazendo perguntas variadas, principalmente com as (os) mais velhas (os), que tinham muitas histórias das (dos) suas (seus) antepassadas (os) para contar.

7) Cinema na escola: filme Kiriku, que trata da lenda do bebê guerreiro que salvou sua aldeia da feiticeira. O filme mostra, em vários momentos, a cultura subsaariana, como as vestimentas, a musicalidade, a relação com a natureza, história da árvore do baobá, entre outras.

8) Livro didático de História: foi possível contextualizar o conteúdo do livro com as atividades práticas feitas até então, de forma crítica.

9) Boneca Abayomi: a partir do livro "As Bonecas Negras de Lara", da autora Aparecida de Jesus Ferreira. O livro foi trabalhado durante um mês, sendo possível fazer oficinas de abayomis, aquela que "traz felicidade". As bonecas eram feitas de pedaços de tecido que as mães, nos navios negreiros, tiravam dos seus vestidos para acalentar seus filhos. Foram desenvolvidas atividades manuais, baseadas em uma história do amor da mãe pelo seu filho: a) Oficina de abayomis para todas as turmas da escola; b) Oficina de abayomis em outras escolas da Rede Municipal de Educação de Ponta Grossa; c) Oficina de abayomis para os pais.

10) Obra de arte: versão negra Abaporu, após um estudo sobre a arte brasileira e sobre Tarsila do Amaral.

11) Instrumento musical: ganzá ou mineiro 
12) Receita afro-brasileira: Canjica, depois de ser trabalhada a receita em sala, a merendeira trouxe na hora do lanche para todos, para ser apreciada.

13) Conhecendo a autora: as (os) alunas (os) gostaram muito do livro trabalhado, "As Bonecas Negras de Lara", e algumas (uns) foram visitar a autora, Aparecida de Jesus Ferreira, em uma de suas palestras na Prefeitura Municipal de Ponta Grossa. As (os) alunas (os) levaram uma carta convidando-a para visitar a nossa escola.

14) Visita da autora a escola: A autora, Aparecida de Jesus Ferreira, aceitou o convite, e veio até a escola, onde foi recebida com uma dramatização do seu livro, além da declamação do poema "Pessoas são diferentes" (Ruth Rocha) e também com a luta de origem africana, Maculelê. A autora conversou com todas (os) as (os) alunas (os), falou sobre como surgiu seu livro "As Bonecas Negras de Lara" e abriu a roda para perguntas.

15) Entrevista: Com a nigeriana Aransiola Jane Tope, que veio ao Brasil para estudar na Universidade Estadual de Ponta Grossa (UEPG) através de um intercâmbio. Ela explanou sobre o continente africano e especificamente sobre seu país, a Nigéria. Contou muitas histórias significativas e deu informações muito ricas sobre a cultura africana (comida, costumes, língua, tribos, religião).

16) Tarde Cultural Afro- Brasileira: A partir de toda experiência vivenciada nesses meses de pesquisa e estudo, sobre a cultura Afro-Brasileira, desenvolveu-se uma tarde agradável de valorização e compartilhamento entre professoras (es), alunas (os) e convidadas (os). As (os) convidadas (os) foram:

Lucélia Clarindo - contadora de história, trouxe seus contos africanos, de forma dinâmica e visual, contando com a participação de todos.

Sociedade Afro-Brasileira Cacique Pena Branca - compartilhou seus conhecimentos sobre a cultura afro- brasileira, desde curiosidades, gastronomia, instrumentos musicais e até receita de cocada para levar aos pais.

Grupo de Capoeira Gingando com Jesus: Depois da apresentação de Capoeira, o grupo reuniu todas (os) em duplas para ensinar noções de capoeira. 
Águas da Cachoeira de Oxum O grupo religioso de origem africana, não compareceu no dia programado.

Cabeleireira e mães: Fizeram lindos penteados nos cabelos de alunas (os) afrosbrasileiras (os), realçando a beleza negra. Para finalizar à tarde cultural houve um desfile com as meninas, meninos e seus belos penteados.

\section{CONSIDERAÇÕES FINAIS}

Desde que o Projeto começou, ele tem se expandido a cada dia, tomando proporções maiores e não vai se esgotar tão cedo, já que o tema é amplo e muito importante. Desta forma, respondemos ao objetivo/pergunta que nos propusemos com este relato de experiência: Quais impactos ocorreram na comunidade com as práticas adotadas de fortalecimento das identidades raciais negras? Muitas questões nos chamaram a atenção de forma positiva. São elas:

Todos as professoras (es) se envolveram no tema, a princípio só em sala de aula com suas (seus) alunas (os). Aos poucos, estavam todas (os) debatendo questões de atos de racismos diários que vemos e ouvimos nas mídias em geral, que é uma questão abordada no Letramento Racial Crítico. Algumas (uns) até mesmo comprando bonecas negras às suas filhas e netas, afirmando ter comprado devido à consciência adquirida a partir do projeto. Uma servente negra, que até então não tinha se posicionado em relação e este tema, sentiu-se confortável em dar seu importante testemunho.

$\mathrm{Na}$ comunidade não foi diferente, mães e pais vindo nos parabenizar pelos debates, dizendo que as (os) filhas (os) comentam e condenam posturas racistas em casa e na rua. A gratidão dos funcionários do posto de saúde, do CMEl, da Colônia Sutil, das escolas visitadas pelo projeto.

O projeto foi gratificante às (aos) alunas (os), à medida que foram debatendo os assuntos expostos como a cultura africana, a diversidade, entre outros. Foram se tornando mais críticos e fazendo perguntas cada vez mais pertinentes ao tema, querendo saber cada vez mais. A descoberta, por elas (es) da cultura africana e afro-brasileira e da sua importância para a constituição do nosso país, fez com que algumas (uns) alunas (os), negras (os) que antes tinham vergonha do seu cabelo, por exemplo, o assumissem de forma plena. 
Concluímos que o projeto transcendeu os muros da escola, e foi muito além de um debate interno. Com certeza, com esse projeto os olhares se modificaram, tanto das (os) professoras (es), alunas (os), e funcionárias (os), quanto da comunidade local. Com todo esse trabalho realizado, que envolveu alunas (os), professoras (es), demais funcionárias (os) e a comunidade em geral, acreditamos que contribuímos por melhorias tanto para desconstruir expressões e ações racistas, quanto para colocar a escola mais próxima da comunidade, como por exemplo, a reativação do clube de mães, que há anos não funcionava. Sua proposta inicial será trabalhar o tema cultural afro-brasileiro com reuniões quinzenais, quem sabe até para, num primeiro momento, confeccionar as bonecas abayomi.

Outro resultado positivo deste projeto são os convites para que a escola participe de eventos em outros locais, para chamar a atenção a um tema tão urgente e importante na atualidade, que é a luta antirracista. Certamente promoveu o Letramento Racial Crítico na comunidade e foi além dos muros da escola, alcançando a sociedade de forma mais abrangente.

\section{REFERÊNCIAS}

ARANSIOLA, T. J. Mulher negra africana: uma narrativa autobiográfica das experiências de uma nigeriana e suas relações com o feminismo negro. Travessias, Cascavel, v. 13, n. 3, p. 123-135, 2019.

ARANTES, V. A. (Org.). Afetividade na escola: alternativas teóricas e práticas. São Paulo: Summus Editorial, 2003.

BRASIL. Lei $\mathbf{n}^{\circ} \mathbf{1 0 . 6 3 9}$, de 9 de janeiro de 2003. Altera a Lei $n^{\circ}$ 9.394, de 20 de dezembro de 1996, que estabelece as diretrizes e bases da educação nacional, para incluir no currículo oficial da Rede de Ensino a obrigatoriedade da temática "História e Cultura Afro-Brasileira", e dá outras providências. Brasília, 2003.

BRASIL. Ministério da Educação. Diretrizes Curriculares Nacionais para a Educação das Relações Étnico-Raciais e para o Ensino de História e Cultura Afro-Brasileira e Africana. Brasília, 2005.

CAVALLEIRO, E. S.; GOMES, J. V. Do silêncio do lar ao silêncio escolar: racismo, preconceito e discriminação na educação infantil. São Paulo: Contexto, 1998.

CLARINDO, L. Contos Africanos. Ponta Grossa, Escola Municipal Professora Kazuko Inoue, 2017. (Comunicação Oral).

DIAS, L. R. Cada um com seu jeito, cada jeito é de um! llustradora: Sandra Beatriz Lavandeira. Campo Grande: Editora Alvorada, 2012.

FERREIRA, A. J. Letramento Racial Crítico através de narrativas autobiográficas: com atividades reflexivas. Ponta Grossa: Estúdio Texto, 2015a.

FERREIRA, A. J. Narrativas Autobiográficas de Professoras (es) de Línguas na Universidade: Letramento Racial Crítico e Teoria Racial Crítica. In: FERREIRA, A. J. 
Narrativas Autobiográficas de Identidades Sociais de Raça, Gênero, Sexualidade e Classe em Estudos da Linguagem. Campinas, SP. Pontes Editora, 2015b, p. 127-160. FERREIRA, A. J. As Bonecas Negras de Lara. Ilustrador: Élio Chaves. Ponta Grossa: ABC Projetos, 2017.

GOMES, N. L. Trajetórias escolares, corpo negro e cabelo crespo: reprodução de estereótipos ou ressignificação cultural? Revista Brasileira de Educação, n. 21, Set./ Out./Dez. 2002.

GRUPO DE CAPOEIRA GINGANDO COM JESUS. Capoeira. Ponta Grossa, Escola Municipal Professora Kazuko Inoue, 2017. (Comunicação Oral).

KIRIKOU et la Sorcière (Kiriku e a Feiticeira). Direção e produção: Michel Ocelot. França: filme, 1998. Diponível em: https://filmow.com/kiriku-e-a-feiticeira-t8176/. Acesso em: 10 de maio 2017.

LUNGOV. M.; FUNARI, R. S. História. 6 ed. São Paulo: Edições SM, 2017. 128 p. (Coleção Aprender Juntos, $3^{\circ}$ ano).

MERCADO, L. P. L. Formação continuada de professores e novas tecnologias. Ufal, 1999.

MORIN, E. A Cabeça Bem-Feita: repensar a reforma - reformar o pensamento. Bertrand Brasil, v. 99, Rio de Janeiro, 2000.

OLIVEIRA, C. L; MOURA, D. G. Metodologia de projetos e ambientes não formais de aprendizagem: indício de eficácia no processo do ensino de Biologia. In: ATAS DO V ENPEC - ENCONTRO NACIONAL DE PESQUISA EM EDUCAÇÃO EM CIÊNCIAS, 5, 2005, Bauru: Atas. ABRAPEC, 2005. Disponível em: http://www.nutes.ufrj.br/abrapec/ venpec/conteudo/oralarea4.htm. Acesso em: 18 de ago. 2017.

SILVA, T. T. (Org.). Identidade e diferença: a perspectivas dos estudos culturais. Petrópolis: Vozes, 2000.

SOCIEDADE AFRO-BRASILEIRA CACIQUE PENA BRANCA. Gastronomia, Receitas, Instrumentos Musicais e Curiosidades. Ponta Grossa, Escola Municipal Professora Kazuko Inoue, 2017. (Comunicação Oral).

SOUZA, E. Penteados Afros. Ponta Grossa, Escola Municipal Professora Kazuko Inoue, 2017. (Comunicação Oral). 


\begin{abstract}
This work proposes to bring some reflections about a project carried out in a municipal school in the initial grades of elementary school, which discussed, fundamentally, racial identities. It started from the experience with black children reflecting on their racial identities. The aim was to understand what impacts would occur in the community with the practices adopted to strengthen black racial identities. For this discussion, we used the theoretical resources such as, Cavalleiro (1998); Ferreira (2015a, 2015b); Gomes (2002); Silva (2000); Oliveira (2005). From a methodological point of view, this is the project methodology, supported by Critical Racial Literacy (FERREIRA, 2015b). As a result, we emphasize the development of children's criticality, the involvement of all school employees and also, the transposition of the debate beyond the school walls, which in this way was able to bring new views to the theme racial identities at school and the promotion of critical race literacy.
\end{abstract}

KEYWORDS

Racism; Childhood; School; Critical Race Literacy

AFRICA AND BRAZIL: PEOPLE'S KNOWLEDGE IN FAVOR OF CRITICAL RACE LITERACY

Samantha Schäfer Mestranda em Estudo da Linguagem - Universidade Estadual de Ponta Grossa Aparecida de Jesus Ferreira Doutora em Letras • University of London 